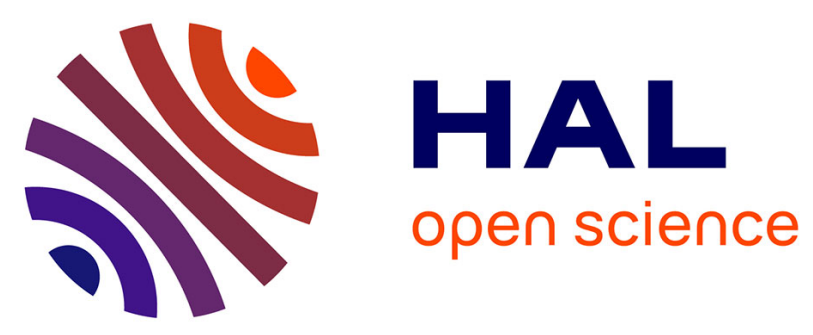

\title{
Vertical propagation of wave perturbations in the middle atmosphere on Mars by MAVEN/IUVS
}

Hiromu Nakagawa, Naoki Terada, Sonal K. Jain, Nicholas M. Schneider, Franck Montmessin, Roger V. Yelle, Fayu Jiang, Loïc Verdier, Scott L. England, Kanako Seki, et al.

\section{To cite this version:}

Hiromu Nakagawa, Naoki Terada, Sonal K. Jain, Nicholas M. Schneider, Franck Montmessin, et al. Vertical propagation of wave perturbations in the middle atmosphere on Mars by MAVEN/IUVS. Journal of Geophysical Research. Planets, 2020, 125 (9), pp.e2020JE006481. 10.1029/2020JE006481. insu-02937040

\section{HAL Id: insu-02937040 \\ https://hal-insu.archives-ouvertes.fr/insu-02937040}

Submitted on 4 Mar 2021

HAL is a multi-disciplinary open access archive for the deposit and dissemination of scientific research documents, whether they are published or not. The documents may come from teaching and research institutions in France or abroad, or from public or private research centers.
L'archive ouverte pluridisciplinaire HAL, est destinée au dépôt et à la diffusion de documents scientifiques de niveau recherche, publiés ou non, émanant des établissements d'enseignement et de recherche français ou étrangers, des laboratoires publics ou privés. 


\section{RESEARCH ARTICLE \\ 10.1029/2020JE006481 \\ Key Points: \\ - MAVEN/IUVS revealed for the first time the global characteristics of wave perturbations in temperature profiles from 20 to $140 \mathrm{~km}$ altitude \\ - The peak amplitudes of waves exceed $20 \%$ of the mean background values on the nightside, larger than those in Earth's mesosphere \\ - Amplitudes appear to grow with height for longer wavelengths, whereas dissipation of shorter wavelengths occur}

Correspondence to:

H. Nakagawa,

hnakagawa@tohoku.ac.jp

\section{Citation:}

Nakagawa, H., Terada, N., Jain, S. K., Schneider, N. M., Montmessin, F., Yelle, R. V., et al. (2020). Vertical propagation of wave perturbations in the middle atmosphere on Mars by MAVEN/IUVS. Journal of Geophysical Research: Planets, 125, e2020JE006481. https://doi.org/10.1029/2020JE006481

Received 13 APR 2020

Accepted 31 AUG 2020

Accepted article online 10 SEPT 2020

\section{Vertical Propagation of Wave Perturbations in the Middle Atmosphere on Mars by MAVEN/IUVS}

\author{
Hiromu Nakagawa' $^{1}$ (D), Naoki Terada ${ }^{1}$ (D), Sonal K. Jain ${ }^{2}$ (D), Nicholas M. Schneider² (iD, \\ Franck Montmessin ${ }^{3}$ (D), Roger V. Yelle ${ }^{4}$ (D) Fayu Jiang ${ }^{4}$, Loic Verdier ${ }^{3}$, Scott L. England ${ }^{5}$ (D), \\ Kanako Seki $^{6}$ (D), Hitoshi Fujiwara ${ }^{7}$, Takeshi Imamura ${ }^{8}$ (D), Nao Yoshida ${ }^{1}$ (D), Takeshi Kuroda ${ }^{1}$ (D), \\ Kaori Terada $^{1}$ (D), Hannes Gröller ${ }^{2}$ (D), Justin Deighan ${ }^{4}$ (D), and Bruce M. Jakosky ${ }^{4}$ (D) \\ ${ }^{1}$ Graduate School of Science, Tohoku University, Sendai, Japan, ${ }^{2}$ Laboratory for Atmospheric and Space Physics, \\ University of Colorado, Boulder, CO, USA, ${ }^{3}$ Laboratoir Atmosphères, Milieux, Observations Spatiales (LATMOS), UVSQ, \\ Université Paris-Saclay, Sorbonne Université, CNES, Paris, France, ${ }^{4}$ Lunar and Planetary Laboratory Science, University \\ of Arizona, Tucson, AZ, USA, ${ }^{5}$ Aerospace and Ocean Engineering, Virginia Tech, Blacksburg, Blacksburg, VA, USA, \\ ${ }^{6}$ Graduate School of Science, The University of Tokyo, Tokyo, Japan, ${ }^{7}$ Faculty of Science and Technology, Seikei \\ University, Tokyo, Japan, ${ }^{8}$ Graduate School of Frontier Sciences, The University of Tokyo, Tokyo, Japan
}

Abstract This work offers the first in-depth study of the global characteristics of wave perturbations in temperature profiles at $20-140 \mathrm{~km}$ altitudes derived from the Imaging Ultraviolet Spectrograph (IUVS) onboard the Mars Atmosphere and Volatile EvolutioN (MAVEN) spacecraft. The peak amplitudes of waves seen in temperature profiles exceed $20 \%$ of the mean background, especially on the nightside, which is larger than those in Earth's mesosphere and thermosphere. The wave perturbations generate an instability layer around $70-100 \mathrm{~km}$ on the nightside, which potentially causes wave-breaking and turbulences. Our results highlighted a seasonal variation in the latitudinal distribution of nightside perturbations. Amplitudes of wave perturbations were found to be large in the northern low-latitude region and the southern polar region during the first half of the year $\left(L_{s}=0-180^{\circ}\right)$. An increase of waves in the spectral density was found in southern low-latitude regions in the latter half of the year $\left(L_{s}=180-360^{\circ}\right)$. Vertical wavenumber spectral density in the Martian middle atmosphere shows a power-law dependence with a logarithmic spectral slope of -3 , similar to the features seen in the Earth's atmosphere. The derived spectral power density suggests the longer waves growing with height while the effective dissipation of shorter waves occurs. The strong $\mathrm{CO}_{2}$ 15-micron band cooling can effectively dissipate shorter waves. In contrast, the spectral power density at longer waves suggests an amplitude growth with height of unsaturated waves up to the lower thermosphere.

Plain Language Summary Atmospheric waves are recognized as an important part of the terrestrial climate system. This work offers the first in-depth study of the global characteristics of wave perturbations in temperature profiles in the Martian middle atmosphere. The peak amplitudes of waves seen in temperature profiles exceed $20 \%$ of the mean background, especially on the nightside, which is larger than those in Earth's mesosphere and thermosphere. We find that the wave perturbations generate an instability layer around $70-100 \mathrm{~km}$ on the nightside. The longer waves suggest the amplitudes grow with height which becomes large enough to distort the Martian upper atmosphere significantly.

\section{Introduction}

Internal gravity waves are recognized as an important part of the terrestrial climate system. They are ubiquitous in the Earth's upper atmosphere (Bruinsma \& Forbes, 2008; Fritts, 2011; Hocke \& Schlegel, 1996) and affect the dynamics, composition, and thermal structure of the terrestrial middle atmosphere (see the seminal review of Fritts \& Alexander, 2003) and thermosphere (see the review of Yiğit et al., 2016). Global characteristics of gravity waves on Earth have been extensively investigated for decades (Forbes et al., 2016; John \& Kumar, 2012; Tsuda \& Nishida, 2000; X. Liu et al., 2017).

On Mars, large fluctuations in density and temperature with short vertical wavelengths for vertical wavelength $<10 \mathrm{~km}$ were first detected in Viking, Opportunity, Spirit, and Mars Pathfinder entry probes (Magalhaes et al., 1999; Seiff \& Kirk, 1976). Wave amplitudes in the Martian atmosphere are larger than those in the terrestrial atmosphere and the important role of gravity waves of tropospheric origin in the middle atmosphere has been appreciated in early modeling studies (Barnes, 1900; Joshi et al., 1995). Gravity
(C)2020. American Geophysical Union. All Rights Reserved. 
waves strongly affect the large-scale winds, thermal balance, and density in the mesosphere and lower thermosphere (e.g., Medvedev et al., 2011, 2015, 2016). The temperature perturbations induced by gravity waves facilitate mesospheric $\mathrm{CO}_{2}$ ice cloud formation (González-Galindo et al., 2011; Spiga et al., 2012; Yiğit et al., 2015). Thermal tides are dominant with persistent wave modes that produce the largest variations in the temperature profiles (e.g., England et al., 2016, 2019). Tidal-gravity wave interactions are expected to occur on Mars (Heavens et al., 2010). The observed polar warmings (McClees et al., 2008) are related to adiabatic heating in the downwelling branch of the single, nearly pole-to-pole Hadley circulation which has its downward branch at high northern winter latitudes, with a further contribution due to thermal tides, planetary, and gravity waves (e.g., Wilson, 1997).

Most of the information about small-scale waves on Mars at altitudes from 0 to $40 \mathrm{~km}$ has been obtained from radio occultation techniques (Ando et al., 2012; Creasey et al., 2006; Tellmann et al., 2013), temperature profiles retrieved from the Mars Climate Sounder radiometer onboard Mars Reconnaissance Orbiter (MRO/ MCS) (Heavens et al., 2020), and airglow observations by the Observatoire pour la Minéralogie, l'Eau, les Glaces et l'Activité onboard Mars Express (MEX/OMEGA) (Altieri et al., 2012). They found a horizontal wavelength of 50-150 km in the airglow. Creasey, Forbes, and Keating (2006) showed an enhancement of wave energy associated with small-scale disturbances over the tropics and mountains in the lower atmosphere (10-30 km). Recently, a high-resolution (gravity wave-resolving) Martian general circulation model (MGCM) has been applied for investigation of gravity wave activity in the troposphere and vertical propagation of gravity waves in the middle atmosphere (Kuroda et al., 2015, 2016, 2019). The simulated distributions of gravity wave energy in the lower atmosphere support the observational evidence of wave enhancement in the equatorial zone (Ando et al., 2012; Creasey, Forbes, \& Keating, 2006). However, previous radio occultation observations have been restricted to a certain local-time. Therefore, local-time dependence of wave perturbations in the lower atmosphere has remained unexplored. Heavens et al. (2020) presented the most comprehensive evaluation of gravity wave activity of lower atmosphere and suggest the contributions from convective processes in addition to those associated with topographic features.

In the upper atmosphere, wave perturbations were quantified using aerobraking measurements. Aerobraking of Mars Global Surveyor (MGS) at 100-130 km showed relative density perturbations of 5$50 \%$ with dominant horizontal wavelengths of 20 to $300 \mathrm{~km}$ (Creasey et al., 2006; Forbes et al., 2006; Fritts et al., 2006). In contrast to the lower atmosphere, no difference between tropical and extratropical density perturbations in the thermosphere has been found in observations (Creasey, Forbes, \& Hinson, 2006). Since previous studies did not establish a correlation between wave activity in the lower and the upper atmosphere, questions about sources of waves in the thermosphere and their possible links with those in the troposphere still remain to be addressed. The most extensive body of observations in the Martian middle atmosphere has been obtained using the Spectroscopy for Investigation of Characteristics of the Atmosphere of Mars (SPICAM) onboard MEX (Forget et al., 2009; González-Galindo et al., 2011; McDunn et al., 2006; Montmessin et al., 2006, 2017; Quémerais et al., 2006). These observations revealed the density and thermal structures in the Martian mesosphere and lower thermosphere, and have refined our understanding of the Martian upper atmosphere. Withers et al. (2011) performed interesting work on large-scale wave characterization, such as zonal wavenumber 2 and 3 (henceforth wave- 2 and wave-3, etc.), with SPICAM data at 70-120 km altitudes. However, small-scale perturbations in this altitude region have not been addressed in detail.

Since October 2014, NASA's Mars Atmosphere and Volatile EvolutioN (MAVEN) mission has performed a comprehensive study of the Martian atmosphere (Jakosky et al., 2015, 2018). In situ measurements of the upper atmosphere, from $300 \mathrm{~km}$ down to $130 \mathrm{~km}$, revealed that wave perturbations ubiquitously exist in the populations of ions and neutrals in the upper thermosphere (Bougher et al., 2015; England et al., 2017; Siddle et al., 2019; Terada et al., 2017; Vals et al., 2019; Yiğit et al., 2015). Wave perturbations have also been detected by remote sensing with the Imaging Ultraviolet Spectrograph (IUVS) onboard MAVEN at altitudes between 20 and $140 \mathrm{~km}$ (Gröller et al., 2015, 2018). These IUVS measurements provide opportunities for investigating possible links between waves in the Martian troposphere and thermosphere.

In order to improve our knowledge of the global characteristic of waves, we use a set of IUVS stellar occultation measurements to obtain temperature perturbations in the middle atmosphere during the period from 24 March 2015 to 12 April 2018, which spans two Martian Years. Sections 2 and 3 describe the IUVS stellar 
occultation data, derived temperature profiles, and the wave amplitudes as a function of the solar zenith angle, local-time, and background temperature throughout the period. The global distribution of waves and seasonal variations are presented in section 4 . The observed vertical wavenumber spectral densities are presented in section 5. Discussion and conclusions are given in sections 6 and 7.

\section{MAVEN/IUVS Stellar Occultation Measurements}

The IUVS instrument measures electromagnetic radiation in two spectral channels: the Far-UV (110$190 \mathrm{~nm}$ ) and Mid-UV (170-350 nm). During a stellar occultation, the two channels allow remote sounding measurements to be taken in the 20 to $140 \mathrm{~km}$ altitude range. The well-controlled Articulated Payload Platform (APP) on the MAVEN spacecraft enables the specific pointing of the instrument (McClintock et al., 2014) to star, thus permitting IUVS stellar occultation measurements to obtain good spatial coverage for latitude, longitude, local-time, and season. Occultations are executed in campaigns lasting 1-2 days. The MAVEN/IUVS stellar occultation campaigns have been performed every 2 months since 24 March 2015. In this study, we apply the data set between March 2015 and April 2018 almost two Martian Years. The vertical resolution of the retrieved temperature profiles varies from 2 to $10 \mathrm{~km}$ (Gröller et al., 2015). The 678 temperature profiles are adopted, that have altitude sampling better than $6 \mathrm{~km}$ and an altitude coverage large enough $(>20 \mathrm{~km}$ ) to detect wave signatures between 20 and $140 \mathrm{~km}$ during the first half of the year (423 profiles in solar longitude, $\left.L_{S}=0-180^{\circ}\right)$, and the latter half of the year $\left(255\right.$ profiles in $\left.L_{s}=180-360^{\circ}\right)$. The list of the stellar occultation campaigns from \#1 to \#19 presented in this study are summarized in Table 1.

Figure 1 shows the distributions of the tangential footprints (as the coordinates of the closest approach distance along the line of sight) of the IUVS stellar occultation measurements. The color code represents each occultation campaign. A campaign of observations in consecutive orbits roughly covers the whole latitudinal circle. The targeted UV bright stars were selected for optimizing a specific latitude coverage at a certain season. The IUVS measurements presented in this study cover the latitude ranges between $70^{\circ} \mathrm{N}$ and $80^{\circ} \mathrm{S}$. The geometrical parameters of the tangential footprint of the occultation evolved throughout the mission. Thus, we have to note that the results shown here represent a combination of these geometrical variations and real atmospheric variations. An altitude range between 20 and $140 \mathrm{~km}$ was fully covered on the nightside. In contrast, profiles on the dayside were obtained for altitudes above $100 \mathrm{~km}$ due to the stray light below.

First, $\mathrm{CO}_{2}$ number densities were retrieved from the transmission spectra of stellar signal in the atmosphere at each orbit (Gröller et al., 2015). Next, temperatures were derived from densities under the assumption of hydrostatic equilibrium (e.g., see the works of Gröller et al., 2015; Medvedev et al., 2016). All temperature profiles used in this study correspond to Level 2, version 13, revision 01 data provided by the Planetary Data System (PDS) (https://atmos.nmsu.edu/data_and_services/atmospheres_data/MAVEN/stellar.html) (Schneider, N. et al., MAVEN IUVS Derived-level Data Product Bundle, urn:nasa:pds:maven.iuvs.processed 2015). The line contains both transmission spectrum data (level 1c) and derived data (level 2, temperature and densities). The filename in the PDS contains the keywords, occultation, level 2, version 13, which enables to identify the data set. Temperature disturbance stellar occultation data are available (https://doi.org/ 10.25810/cjvy-vv76), which are custom products which are primarily level 2 data, but the primary extension has been replaced with derived mean component and disturbance component of temperature profiles along with the second-order polynomial fit, and the isolated spectral components of the disturbances, as mentioned below. Gröller et al. (2018) presented a detailed argument to establish the presence of wave perturbations in the profiles, excluding the possibility that such features could arise from an instrumental or data reduction artifact. Gröller et al. (2018) have carefully investigated the possible effects of the Tikhonov regularization smoothing in inversion process, the possible sources of artifacts in the data reduction algorithm, and the periodic motions in spacecraft pointing (see Figures 9 and 10 in Gröller et al., 2018). They concluded that wave perturbations in the derived local densities are a real characteristic of the observed Martian atmosphere.

\section{Temperature Profiles and Wave Signature}

An atmospheric temperature profile $T(z)$ is assumed to consist of a background (mean) component $\langle T(z)\rangle$ and a disturbance (deviation from the mean) $T^{\prime}(z)$. To extract $T^{\prime}(z)$ from a single profile, we applied a second-order polynomial fit between 20 and $140 \mathrm{~km}$ in order to exclude large-scale features, as was similarly done in the analysis of radio occultation data (Ando et al., 2012; Creasey, Forbes, \& Keating, 2006). 
Table 1

List of the Stellar Occultation Campaigns Applied for This Study

\begin{tabular}{|c|c|c|c|c|c|}
\hline Campaign & Date & Martian year (Sols) & Orbit & $\mathrm{L}_{\mathrm{s}}$ & Used profiles \\
\hline 1 & 24-26 March 2015 & $32(585)$ & 00935-00944 & 315 & 14 \\
\hline 2 & 17-18 Мay 2015 & $32(637)$ & 01222-01226 & 344 & 12 \\
\hline 3 & 1-2 August 2015 & $33(43)$ & $01635-01640$ & 22 & 37 \\
\hline 4 & 22-23 September 2015 & $33(93)$ & 01911-01916 & 45 & 0 \\
\hline 5 & 3-4 November 2015 & 33 (134) & 02132-02137 & 64 & 29 \\
\hline 6 & 18-19 January 2016 & $33(208)$ & $02533-02538$ & 97 & 25 \\
\hline 7 & 17-18 March 2016 & $33(265)$ & $02848-02853$ & 124 & 39 \\
\hline 8 & 26-27 May 2016 & $33(334)$ & $03223-03228$ & 159 & 38 \\
\hline 9 & 14-15 July 2016 & $33(381)$ & 03489-03493 & 186 & 45 \\
\hline 10 & 21-22 September 2016 & $33(449)$ & 03856-03865 & 227 & 11 \\
\hline 11 & 16-18 November 2016 & $33(503)$ & 04146-04155 & 263 & 84 \\
\hline 12 & 11-13 January 2017 & $33(558)$ & $04436-04446$ & 298 & 59 \\
\hline 13 & 22-24 March 2017 & $33(626)$ & 04805-04814 & 337 & 30 \\
\hline 14 & 14-15 June 2017 & $34(39)$ & 05246-05254 & 19 & 27 \\
\hline 15 & 5-7 July 2017 & $34(59)$ & 05357-05366 & 29 & 36 \\
\hline 16 & 8-9 October 2017 & $34(152)$ & 05866-05875 & 71 & 27 \\
\hline 17 & 6-8 December 2017 & $34(209)$ & 06193-06202 & 97 & 53 \\
\hline 18 & 7-9 February 2018 & $34(270)$ & $06532-06541$ & 126 & 55 \\
\hline \multirow[t]{2}{*}{19} & 11-12 April 2018 & $34(332)$ & 06866-06875 & 157 & 57 \\
\hline & Total number of profiles & & & & 678 \\
\hline
\end{tabular}

Figures $2 \mathrm{~b}$ and $2 \mathrm{f}$ show a typical example of extracting disturbances $T^{\prime}(z)$ from a single profile of temperature $T(z)$ (2a and 2e) by a polynomial fit derived from Orbit\#2132 on 3rd November 2015 in both the northern (upper panels) and southern (lower panels) hemispheres at $L_{S}=63^{\circ}$. The tangential footprints of the occultation are located at $\left(322^{\circ} \mathrm{E}, 51^{\circ} \mathrm{S}\right)$ and $\left(314^{\circ} \mathrm{E}, 8^{\circ} \mathrm{N}\right)$ in geographical coordinate, respectively. As seen in Figure 2f, the observed temperature profiles exhibit wave perturbations with peak amplitudes which sometimes exceed $20 \%$ of the mean background values in the $20-140 \mathrm{~km}$ altitude range. This is notably larger than those in Earth's mesosphere/thermosphere ( 5-13\%) (e.g., Fritts \& Alexander, 2003; Miyoshi \& Fujiwara, 2008; Suzuki et al., 2007; Yamashita et al., 2013). Comparing Figures $2 \mathrm{c}$ and $2 \mathrm{~g}$, the Brunt-Väisälä frequency, $N^{2}$, is often close to zero in Figure $2 \mathrm{~g}$, which indicates convective instability and possible breakdown of waves in the Martian mesosphere. The presence of
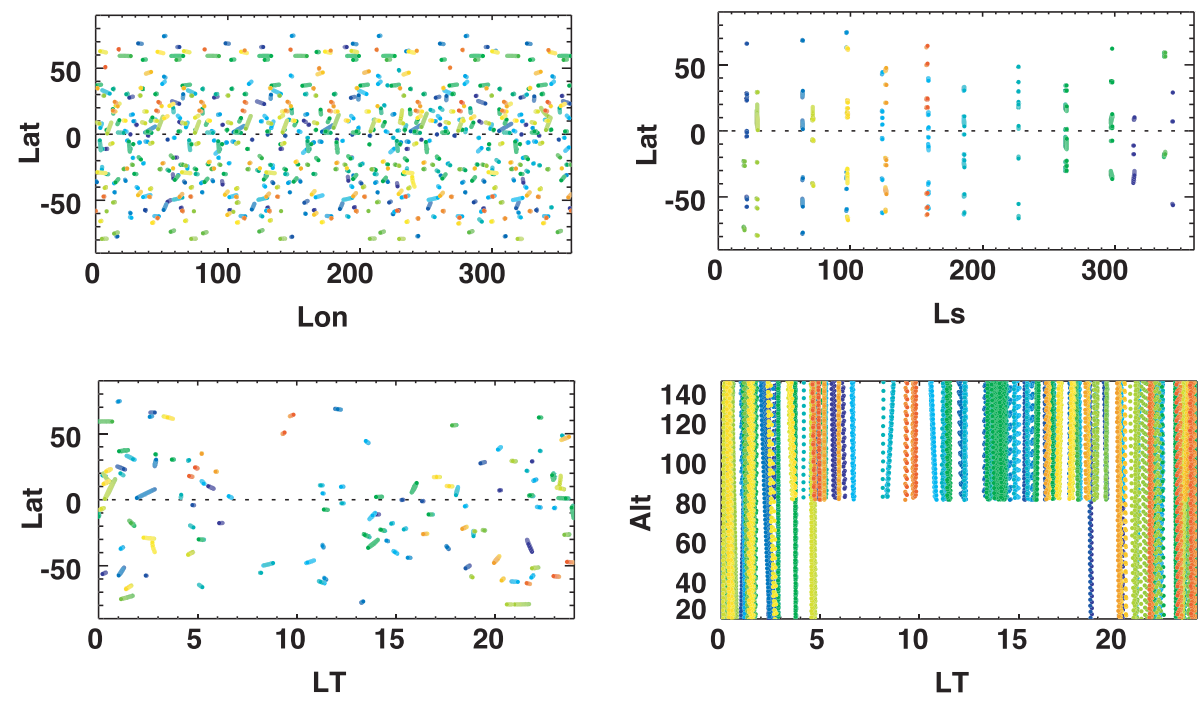

Figure 1. Distributions of the tangential footprints of the IUVS stellar occultation measurements in the coordinates of latitude vs. longitude (a), local-time (b), and solar longitude (d), and in the coordinates of altitude vs. local-time (c). The color code represents each occultation campaign. 
(a)

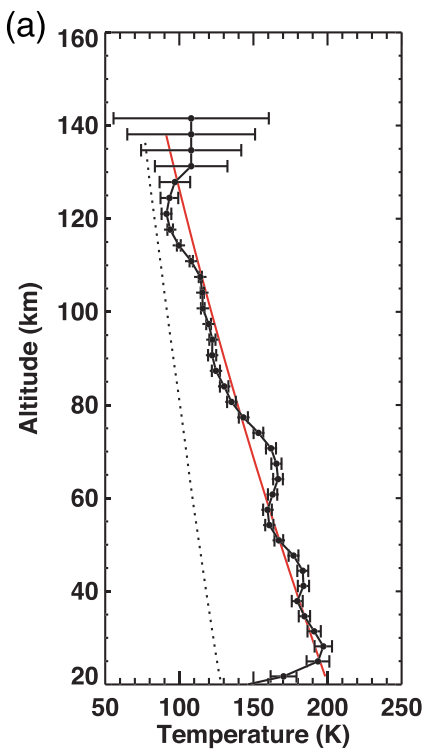

(e)

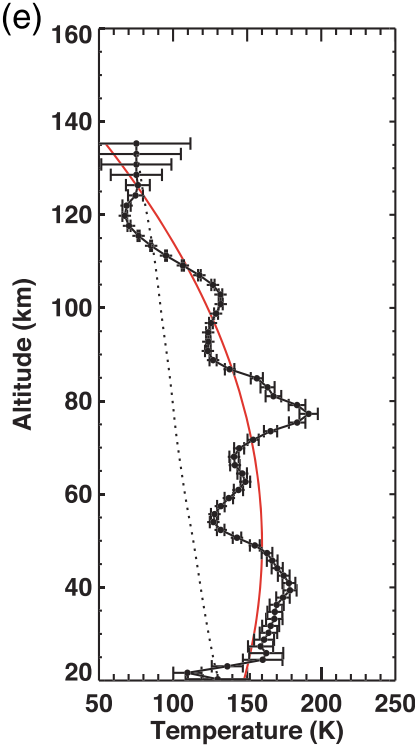

(b)

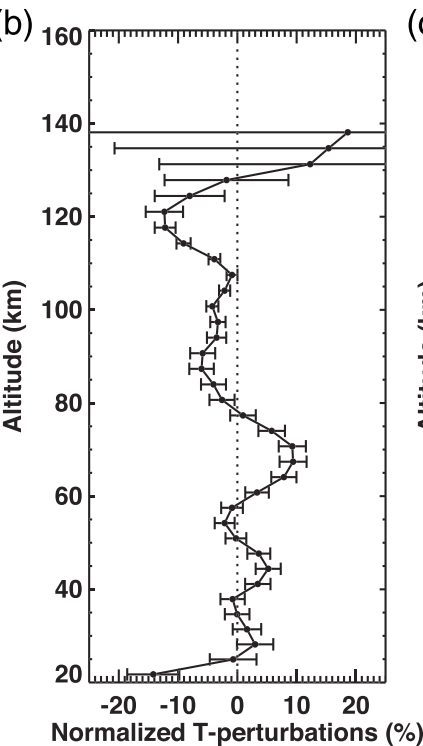

(c)

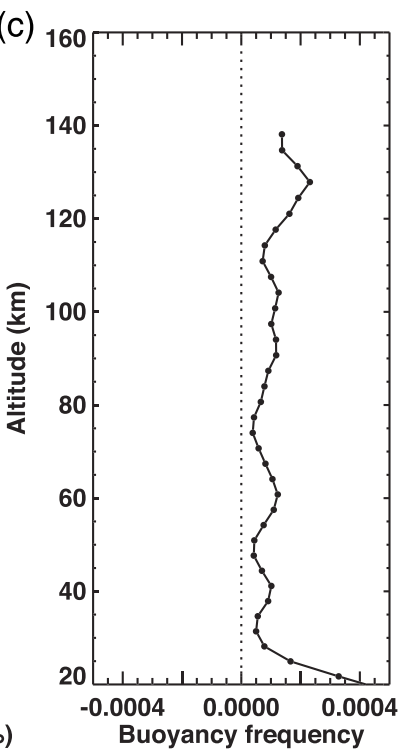

(g)

(f)

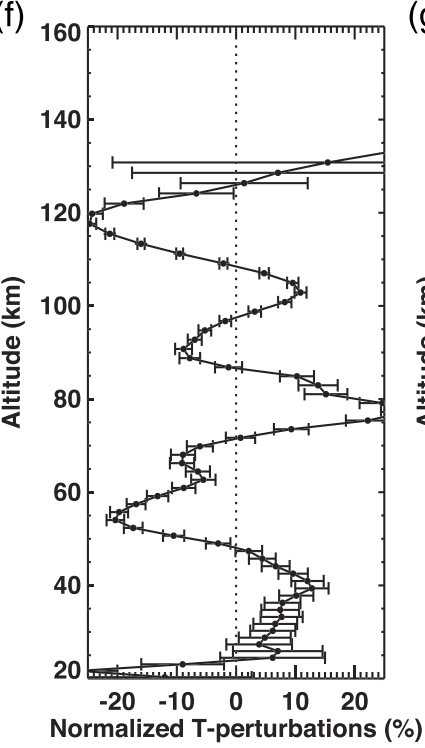

(d)
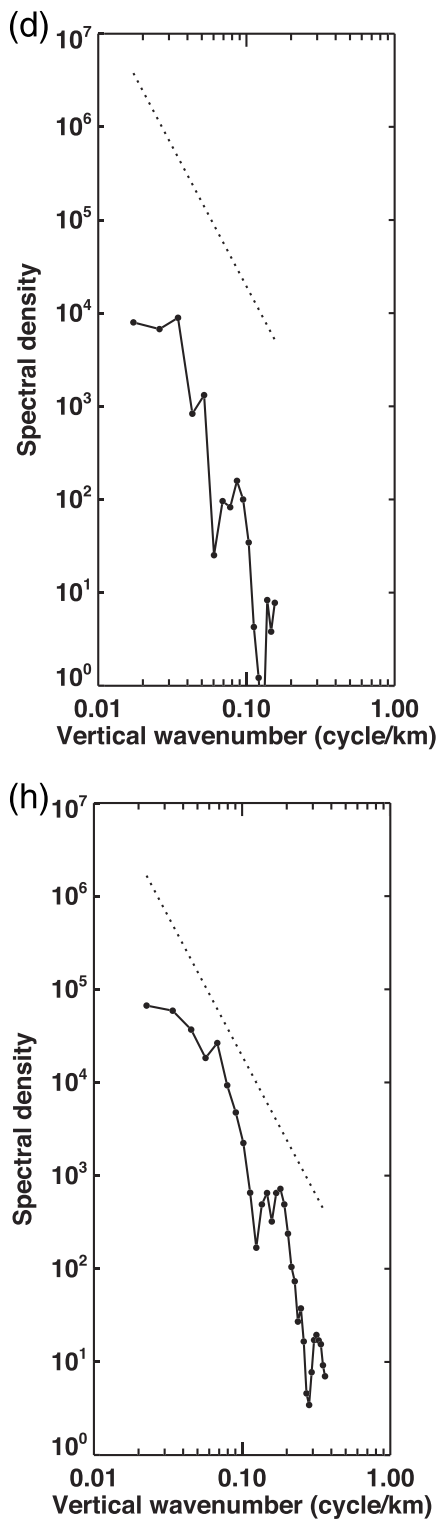

Figure 2. Example of perturbation extractions using an individual polynomial fit derived from Orbit $\# 2132$ on 3 rd November 2015 at $L_{S}=63^{\circ}$. The tangential footprints of the occultation are located at $\left(322^{\circ} \mathrm{E}, 51^{\circ} \mathrm{S}\right)$ and $\left(314^{\circ} \mathrm{E}, 8^{\circ} \mathrm{N}\right)$ in geographical coordinate, respectively. Vertical profiles of temperature $(\mathrm{a}$, e), normalized perturbations (residuals from the fit curve) of temperature (b, f), squared buoyancy frequency (c, g), and vertical spectral power density (d, h) are shown. The solid red line shows the fit. The semiempirical saturation curve is shown for comparison as a dotted line, calculated from Equation 1.

small-scale waves clearly contributes to convective instabilities in the middle atmosphere, as seen in Earth's mesosphere (A. Z. Liu et al., 2004; Collins \& Smith, 2004; Williams et al., 2006).

The present study also obtains vertical wavenumber spectra of waves in the Martian middle atmosphere, as can be seen in Figures $2 \mathrm{~d}$ and $2 \mathrm{~h}$. The spectra are calculated from the normalized temperature perturbations. The minimum vertical wavelength in this study is $\sim 4-12 \mathrm{~km}$ due to the limited vertical resolution $(\sim 2-6 \mathrm{~km})$ of the profile. The Fast Fourier Transform (FFT) can be used to isolate the spectral components of the perturbations. Temperature perturbations in the altitude range of 20-140 $\mathrm{km}$ are analyzed with the FFT including a Hanning window. Because of possible influence from the finite Fourier length, the maximum wavelength analyzed is $\sim 60 \mathrm{~km}$. The extracted waves with the vertical wavelength between 4-12 and $60 \mathrm{~km}$ applied in this study include both gravity waves and thermal tides. A mesoscale model of convective generation of gravity waves (Imamura et al., 2016) suggests that such long-vertical wavelength as long as 
20-50 km waves can be generated and the waves retain their amplitudes up to $150-200 \mathrm{~km}$ altitudes. In Figure $2 \mathrm{~h}$, the vertical wavenumber spectrum divided by $N^{4}$ indicates large spectral density which is close to the semiempirical curve developed for saturated gravity waves in the Earth's atmosphere (Smith et al., 1987; Tsuda et al., 1991):

$$
F_{T^{\prime} / T_{0}}=\frac{1}{4 \pi^{2}} \frac{N^{4}}{10 g^{2} k_{z}^{3}},
$$

where $k_{z}$ is the vertical wavenumber with units of cycles per meter, $T_{0}$ is the background temperature, $N$ is the Brunt-Väisälä frequency, and $g$ is the gravitational acceleration. The present study assumes pure vertical propagation, which may, in some instances, be invalid, but without any theoretical expectation or observational evidence of this not happening at Mars, we think this assumption is reasonable. This then necessarily excludes waves that are propagating close to horizontal such as inertia-gravity waves.

Figure 3 shows the dependences of normalized temperature perturbations, $\left|T^{\prime}(z) / T(z)\right|$, on the solar-zenithangle (SZA) (3a-3d) and background temperature (3e-3h) at each altitude range of 20-50, 50-80, 80-110, and 110-140 km, respectively. The individual amplitude of the waves is averaged over the altitude range. The color code represents the local-time tangential point of the occultations. Note that the dayside profiles were not available at altitudes below $80 \mathrm{~km}$. The averaged amplitudes of each are summarized in Table 2 . As seen in Figures 3a-3d, wave amplitudes on the nightside grow with height, reaching $40-50 \%$ at 110 $140 \mathrm{~km}$. This fact is expected. In contrast, amplitudes of waves on the dayside mostly show less than 10\% at $110-140 \mathrm{~km}$. Consequently, above $80 \mathrm{~km}$, larger amplitudes on the nightside are more than double those found on the dayside. Our result agrees with the in situ measurements in the upper thermosphere obtained during the same time-frame (Siddle et al., 2019; Terada et al., 2017). It is noteworthy that the correlation coefficient increases with height from -0.08 in $20-50 \mathrm{~km}$ to -0.41 in $110-140 \mathrm{~km}$. We find a moderate anticorrelation with background temperature at $110-140 \mathrm{~km}$ altitudes. No correlation at $20-50 \mathrm{~km}$ altitudes may imply a mix of saturation, critical levels, and sources (Vals et al., 2019). Meanwhile, anticorrelation at 100-140 km altitudes may suggest saturation due to convective instability (Terada et al., 2017).

Since the nightside profiles fully cover the altitude range from 20 to $140 \mathrm{~km}$, the nightside profiles are used to obtain the latitude-altitude cross-section and spectral power density, in order to elucidate the upward propagation of waves as detailed hereafter.

\section{Latitudinal-Altitude Cross-Section of Waves}

Based on the nightside profile data set, a latitude-altitude cross-section of the zonally averaged values of I $T(z) \mid$ and $\left|T^{\prime}(z) / T(z)\right|$ are presented for the first half of the year $\left(L_{S}=0-180^{\circ}\right)$ and the latter half of the year $\left(L_{S}=180-360^{\circ}\right)$ as shown in Figure 4. Here the absolute values of normalized temperature perturbations were calculated by averaging over the altitude bin ( $3 \mathrm{~km}$ range) and latitudinal bin ( $3^{\circ}$ width). In Figure $4 \mathrm{~b}$, distinct enhancements around $70-100 \mathrm{~km}$ altitudes have been observed at the equator and northern low latitudes (labeled as A), and southern polar region (labeled as B) at $L_{s}=0-180^{\circ}$. Strong perturbations are also identified above these structures. These regions correspond to the warm atmospheric portions seen in Figure 4a. The observed enhancement of temperature in the middle atmosphere of the southern polar region could be explained by polar warming (McClees et al., 2008). Meanwhile, the observed enhancement at low latitudes in the northern summer hemisphere was not expected, because the nightside of the Martian mesosphere is presumably cold. This is associated with a strong temperature inversion due to the unexpected warm layer which was recently discovered by Nakagawa et al. (2020). This also can be considered as an unstable layer in the mesosphere. Upward propagating waves from below potentially break and deposit their horizontal momentum onto the background mean winds and also create turbulent layer when they encounter the convective instabilities related to the strong temperature inversion due to the warm areas. Strong temperature gradient would produce the convective instabilities which enhance the turbulent flow activities to eliminate the temperature gradient. The dynamical friction effects caused by wave breaking might decelerate the background mean zonal winds in the middle atmosphere, as revealed in the terrestrial atmosphere. The vertical mixing induced by the turbulent layer can influence the homopause and thereby the thermospheric composition. Although we do not have an explanation for such a distinct layer of warm air in the 

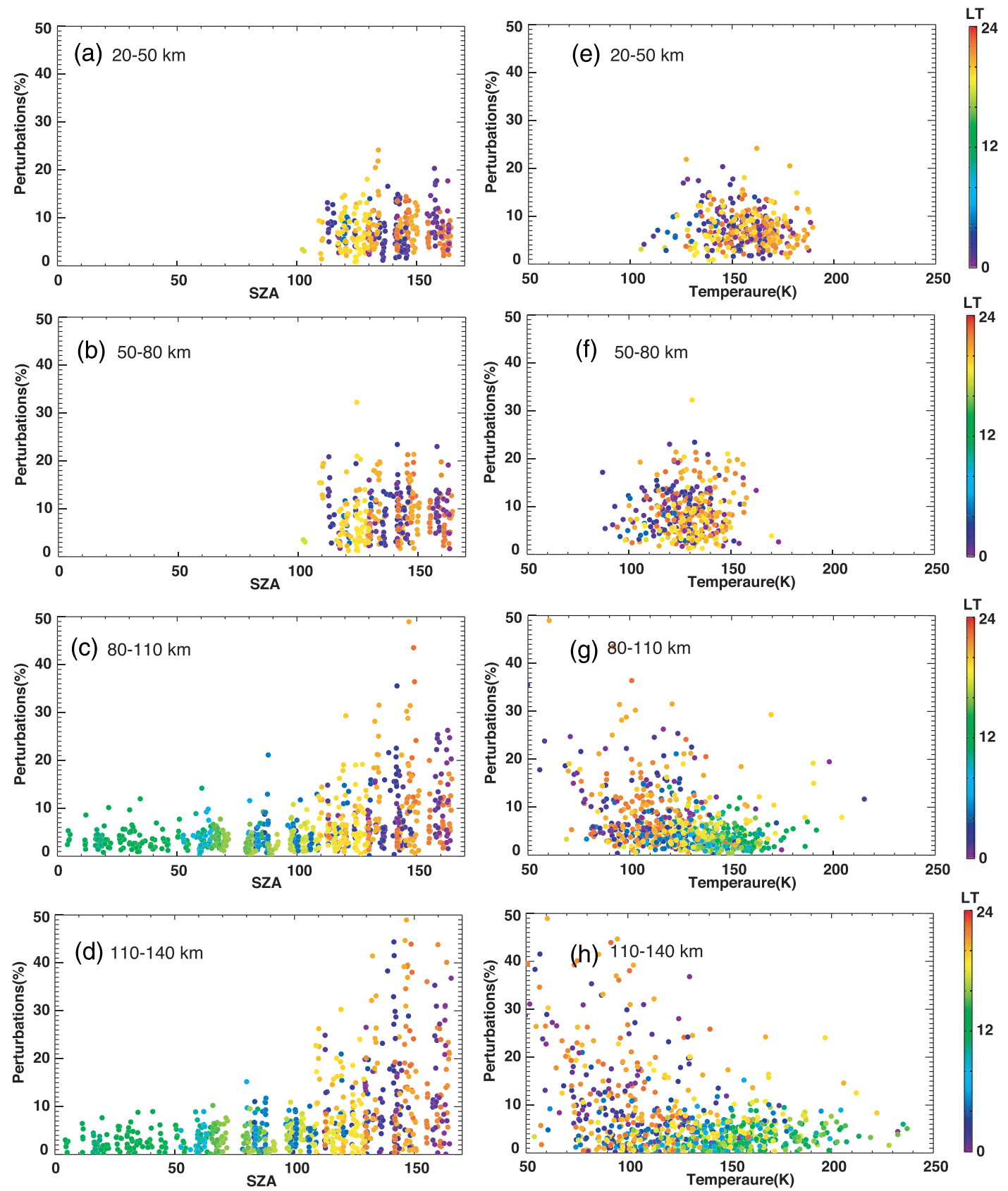

Figure 3. Averaged wave amplitudes as a function of (a-d) solar-zenith-angle (SZA) and (e-h) background temperature. Points are color-coded by local-time at the tangential point of occultations.

\begin{tabular}{|c|c|c|c|c|}
\hline SZA/altitude & $20-50 \mathrm{~km}$ & $50-80 \mathrm{~km}$ & $80-110 \mathrm{~km}$ & $110-140 \mathrm{~km}$ \\
\hline $0-45^{\circ}$ & - & - & 3.58 & 2.86 \\
\hline $45-90^{\circ}$ & - & - & 3.80 & 3.76 \\
\hline $90-135^{\circ}$ & 7.40 & 8.38 & 6.19 & 7.62 \\
\hline $135-180^{\circ}$ & 7.35 & 9.28 & 9.87 & 13.82 \\
\hline
\end{tabular}

mesosphere in the summer night, Nakagawa et al. (2020) suggests evidence of wave-3 structures of warm layer with significant amplitudes that have been interpreted as a signature of diurnal, semidiurnal, and/or stationary planetary waves. This requires future work.

Although the data coverage is limited for the $L_{s}=180-360^{\circ}$ period, it was found that wave activity was quite small in the northern low-latitude region as seen in Figure 4d. The large wave activity in the northern low-latitude region for the $L_{s}=0-180^{\circ}$ period is not 
(a)

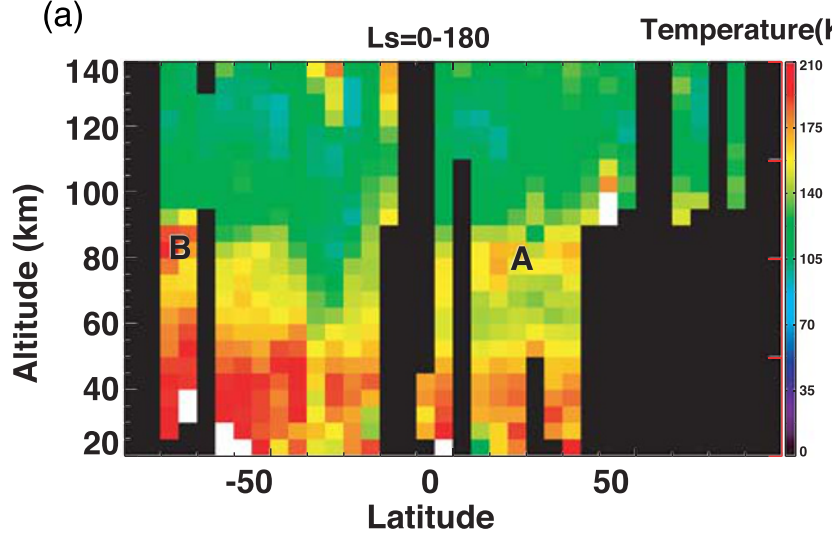

(c)

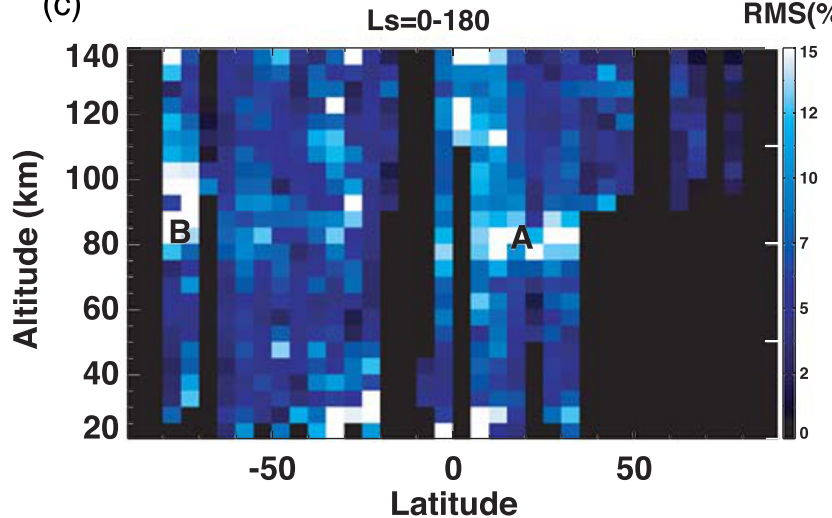

(b)

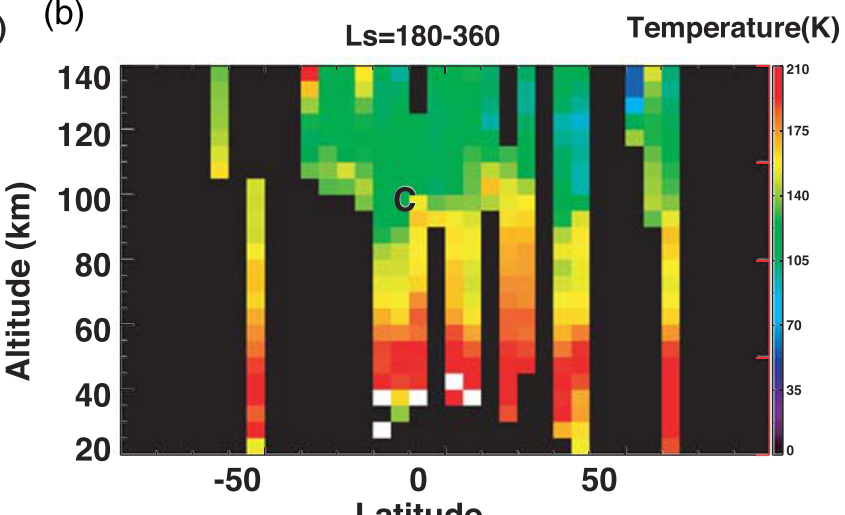

(d)

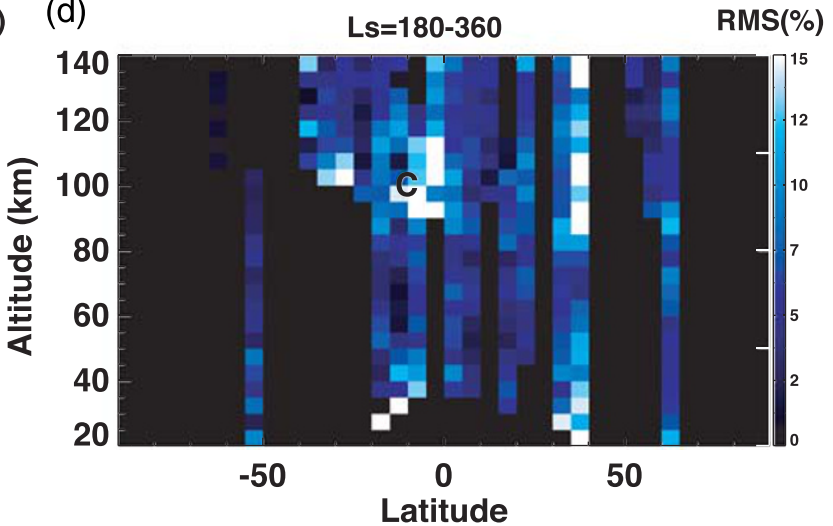

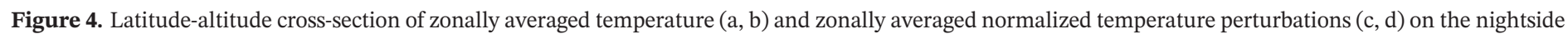
at $L_{S}=0-180^{\circ}$ and $180-360^{\circ}$.

present for the rest of the year. This suggests that the global distribution of temperature perturbations in the middle atmosphere has a strong seasonal dependence. Relatively large amplitudes appeared in the southern low-latitude region above $80 \mathrm{~km}$ altitude (labeled as $\mathrm{C}$ ) in the second half of the year. It is interesting that seasonal variation of gravity wave activity is also visible in the lower atmosphere around 20-30 km altitudes (Heavens et al., 2020). They reported higher activity in northern tropics during the first half of the year than the second half of the year, meanwhile the reverse is true for the southern tropics. Our result also suggests that the seasonal variation of waves implies an enhancement of perturbations in summer low-latitude regions in the mesosphere and lower thermosphere. In contrast, we did not have a chance to address the seasonal variation of the waves at high latitudes due to limited latitudinal coverage.

\section{Vertical Wavenumber Spectral Density of Waves}

By sorting the nightside profiles into two altitudes ranges, $20-90$ and $70-140 \mathrm{~km}$, we are able to examine wave propagation as a function of altitude in the middle atmosphere. Temperature perturbations in the altitude range from 20-90 and 70-140 km are analyzed with the FFT including a Hanning window for each altitude range. Figure 5 shows the averaged vertical wavenumber spectra in the altitude range from 20-90 (dotted lines) and 70-140 km (solid lines) for each season. The color codes correspond to latitudinal range in 50 to $0^{\circ} \mathrm{S}$ (blue), and 0 to $50^{\circ} \mathrm{N}$ (yellow). The number of profiles used in the analysis are summarized in Table 3. We confined our spectral analysis to the low- to middle-latitude region because of the limitation of data coverage for high-latitude region. The obtained spectra show a decline in the spectral density with wavenumber which is similar to those obtained in the terrestrial stratosphere, mesosphere, and thermosphere. The spectral index is typically around -3 at the low wavenumbers. However, the spectra do not compare well with the theoretical spectrum for saturated gravity waves developed for Earth's atmosphere (blackdotted line). This seems to contradict with the fact that the convective instabilities were found in individual 

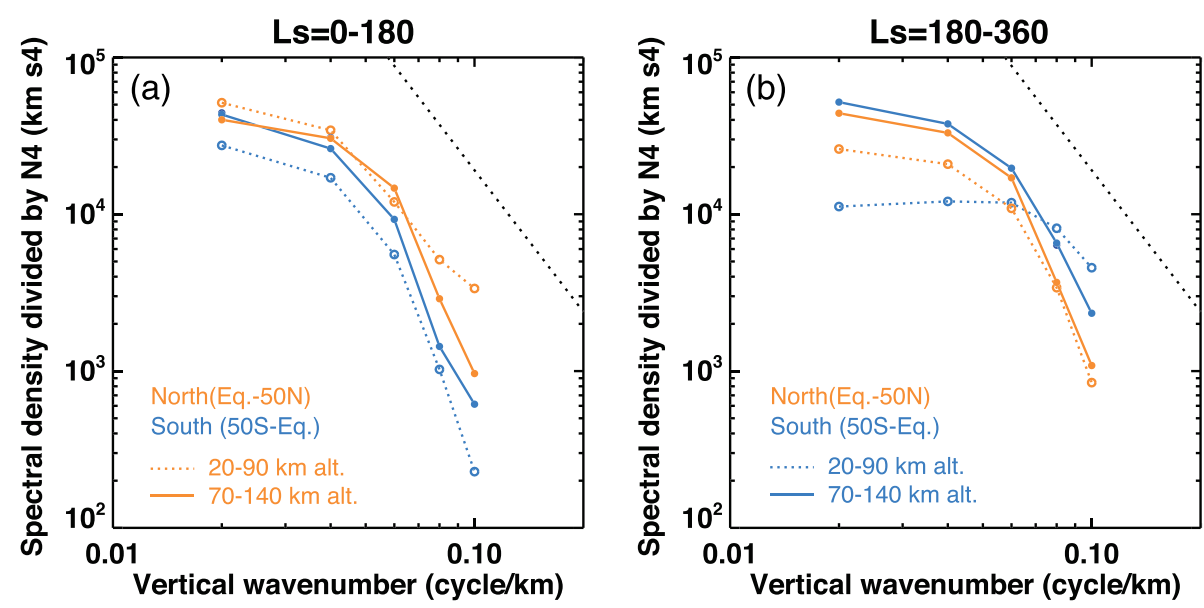

Figure 5. Averaged vertical wavenumber spectra of the temperature perturbations on the nightside normalized by $N^{4}$ in the altitude range of 20-90 km (dotted lines) and 70-140 km (solid lines) at $L_{S}=0-180^{\circ}$ (a) and $L_{S}=180-360^{\circ}$ (b). The semiempirical saturation curve is shown for comparison as the black dotted line. The color lines correspond to latitudinal range in 50 to $0^{\circ} \mathrm{S}$ (blue), and 0 to $50^{\circ} \mathrm{N}$ (yellow).

profiles, as shown in Figure 2. This may indicate a larger statistical weight of unsaturated waves in the averaged spectrum. On the other hand, the spectral density in the Martian lower atmosphere $(<30 \mathrm{~km})$ almost coincides with the saturation curve (Ando et al., 2012). The difference between lower atmosphere and middle atmosphere may indicate that the radiative damping reduces the amplitudes during the vertical propagation from below on Mars.

For the first half of the year, the waves appear to be greater amplitude in the northern hemisphere. During the second half of the year, an increase of waves emerges in the spectral density and is found in the southern hemisphere from $20-90$ and $70-140 \mathrm{~km}$. The spectral power density in summer low-latitude regions suggests slightly larger values than in winter in the $70-140 \mathrm{~km}$ region. This is consistent with the conclusions drawn from Figure 4 . The spectral density at high wavenumbers $\left(\sim 0.10 \mathrm{~km}^{-1}\right)$ in the southern hemisphere increases in the latter half of the year more than in the first half of the year for altitudes in the range $20-90 \mathrm{~km}$. The higher activity in the latter half of the year might suggest that the small-scale waves are intensified by convective processes in the lower atmosphere because perihelion occurs during this period and hence solar heating peaks. The change in the spectral slope at a wavenumber of $0.06 \mathrm{~km}^{-1}$ might suggest that the low-wavenumber region (vertical wavelengths longer than $\sim 17 \mathrm{~km}$ ) is unsaturated and the energy density can potentially increase with altitude. In fact, the spectral power density at low wavenumbers suggests the amplitudes grow with height toward the lower thermosphere in both seasons, except in the northern summer. Considerable wave occurs in the southern summer $\left(L_{s}=180-360^{\circ}\right)$. Meanwhile, we find that the spectral power density at higher wavenumbers $>0.06 \mathrm{~km}^{-1}$ (vertical wavelengths $<\sim 17 \mathrm{~km}$ ) at $70-140 \mathrm{~km}$ is mostly equivalent to or lower than that at 20-90 km, except in the southern winter. This means that shorter waves declined while propagating upward. This could be the result of the strong radiative damping by the $\mathrm{CO}_{2}$ 15-micron band cooling on Mars (20 times than Earth) which could effectively dissipate shorter waves (Eckermann et al., 2011; Imamura \& Ogawa, 1995). However, propagation between 20-90 and 70-140 km is not the same for each season and hemisphere. Different behavior of propagation processes might be explained by refraction and filtering

Table 3

Number of Temperature Profiles on the Nightside Applied in Figure 5

\begin{tabular}{llcc}
\hline $\mathrm{L}_{\mathrm{s}}$ & Latitude & $\begin{array}{c}\text { Profiles } \\
\text { at } 20-90 \mathrm{~km}\end{array}$ & $\begin{array}{c}\text { Profiles } \\
\text { at } 70-140 \mathrm{~km}\end{array}$ \\
\hline $0-180^{\circ}$ & Equator $-50^{\circ} \mathrm{N}$ & 57 & 117 \\
& $50^{\circ} \mathrm{S}-$ Equator & 67 & 99 \\
$180-360^{\circ}$ & Equator-50 $\mathrm{N}$ & 67 & 81 \\
& $50^{\circ} \mathrm{S}-$ Equator & 18 & 39 \\
\hline
\end{tabular}
of upward propagating waves dominated by the background winds (Forbes, 2002). Seasonal difference of $\mathrm{CO}_{2}$ density at high altitudes could also influence the change in radiative damping.

\section{Discussion}

The observed wave amplitudes agree well with the amplitudes of density perturbations in the Martian mesosphere and lower thermosphere reported earlier by in situ measurements (3-30\%) (Creasey, 
Forbes, \& Hinson, 2006). On the other hand, we note that waves with short horizontal scales are not resolved in the remote-sensing occultation measurements due to their integration along the line-of-sight and therefore do not contribute to the disturbances discussed in this paper (e.g., Ando et al., 2015; Chamberlain, 1963; Kursinski et al., 1997). If $H$ is the constant density scale height, $R$ is the distance from the center of Mars at the tangential point $(H / R \ll 1)$, the integration along a tangential line of sight is equal to $\sqrt{2 \pi R H}$ (Ando et al., 2015). For Mars, using $H=6-12 \mathrm{~km}, R=3,520 \mathrm{~km}$, the expression yields $364-515 \mathrm{~km}$. Thus, harmonics with horizontal scales shorter than $\sim 500 \mathrm{~km}$ are possibly not resolved by the instrument due to horizontal averaging. Note that Fritts et al. (2006) and Yiğit, England, et al. (2015) found density perturbations with larger magnitudes (up to 50\%) in the upper thermosphere from in situ measurements with higher horizontal resolution.

A complete understanding of the seasonal and latitudinal variations is prevented by the insufficient data coverage; the IUVS data used in this study do not cover the northern high-latitude region $\left(>50^{\circ} \mathrm{N}\right)$ at $L_{S}=0-180^{\circ}$. It is also obvious that the number of profiles for the period $L_{s}=180-360^{\circ}$ are much smaller than those at $L_{S}=0-180^{\circ}$ as seen in Table 1 . We need additional data coverage for a more reliable evaluation of seasonal and latitudinal variations of wave perturbations, especially at high latitudes. In the case of Earth, Tsuda and Nishida (2000) and Miyoshi et al. (2014) demonstrated that the gravity wave energy at high latitudes is much stronger than that at lower latitudes in the mesosphere/thermosphere, while the gravity wave energy is larger at low latitudes in the stratosphere. The poleward propagation of gravity waves is explained by the fact that the westward jet core in the northern hemisphere moves to higher latitudes with height (Sato et al., 2009). General Circulation Models (GCM) also suggest a strong vertical damping of orographically generated gravity wave harmonics due to preferential filtering by the background winds at low latitudes on Mars and Earth (Kuroda et al., 2015; Medvedev et al., 2011; Yiğit et al., 2012, 2015). A single gravity wave harmonic breaks or dissipates due to a variety of mechanisms when its intrinsic phase speed approaches zero with respect to the background wind. Creasey, Forbes, and Hinson (2006) reported significant density fluctuations in both hemispheres in winter at high latitudes in the upper thermosphere using MGS accelerometer data. An enhancement at low latitudes in the middle atmosphere as seen in this study was not presented in Creasey, Forbes, and Hinson (2006).

On the other hand, our result also suggests occurrence of strong waves at the equator and summer low-latitudes in the middle atmosphere. The expected strong solar heating at the equator and summer low-latitudes in the tenuous atmosphere of Mars induces not only notable tidal waves but also strong convection (Michaels \& Rafkin, 2004; Odaka et al., 1998), which can generate strong, fast gravity waves, which can effectively propagate upward into the upper atmosphere (Imamura et al., 2016). Our result supports the recent study by Heavens et al. (2020) which suggests the gravity waves originated by convective processes. The localized heating by absorption of incoming sunlight on dayside via suspended dust particles is also expected to contribute to localized heating and generate waves in the summer hemisphere. The enhanced region of the waves at low latitudes in the middle atmosphere during a global dust storm could originate from below when the waves have no critical level to encounter and can continue to propagate upward into the mesosphere, as seen in Earth's mesosphere (Miyoshi \& Fujiwara, 2009).

Eckermann et al. (2011) theoretically investigated infrared radiative damping rates and their role in the upward propagation of gravity waves. They demonstrated that infrared radiative damping rates increase with decreasing vertical wavelength in the middle atmosphere and peak at $\sim 50-80 \mathrm{~km}$ altitudes. The results from this model indicate that infrared radiative damping is the dominant process in dissipating gravity waves at altitudes from $\sim 0-50 \mathrm{~km}$ altitudes, and is the dominant process for waves with vertical wavelengths $<10-15 \mathrm{~km}$. Our results given by the comparison of spectral power density between 20-90 and 70-140 km agree well with their theoretical predictions. The thermal damping rate due to $\mathrm{CO}_{2} \mathrm{cooling}$ in the Martian atmosphere is overall about 20 times faster than on Earth, primarily due to the much larger $\mathrm{CO}_{2}$ mixing ratio on Mars. The radiative damping rates show a strong dependence on background temperature, as seen in Equation 13 in Eckermann et al. (2011). The impact is particularly large at 70$120 \mathrm{~km}$ due to the low background temperatures at these altitudes. For example, a uniform $10 \mathrm{~K}$ warmer atmosphere causes a doubling of the radiative damping rate at these altitudes (Eckermann et al., 2011). The unexpected warm layer at altitudes from $60-80 \mathrm{~km}$ reported by Nakagawa et al. (2020) may have an impact on the rates. 
In the upper atmosphere, these waves appear to be large enough to distort the background wind velocity and the thermal structure significantly. Effects of waves propagating from the lower atmosphere on the upper thermosphere dynamics and composition at the exobase are still not fully understood. Wavelike perturbations in the Martian upper thermosphere have been studied with the Neutral Gas Ion Mass Spectrometer (NGIMS) onboard MAVEN (Yiğit, England, et al., 2015). They were found to produce large relative density perturbations of $20-35 \%$ between 160 and $220 \mathrm{~km}$. Most recently, Terada et al. (2017) found using NGIMS data that gravity wave activity is distributed relatively uniformly at the exobase when it is normalized with respect to the background temperature. England et al. (2017) showed that gravity waves with relatively long vertical wavelengths exceeding $100 \mathrm{~km}$ are likely the source of the waves seen by NGIMS in the upper thermosphere. Longer vertical wavelength waves are also seen in our analysis (Figures 2 and 3), although the vertical extent of the data restricts detection of waves with mesoscale wavelengths of $>100 \mathrm{~km}$; Imamura et al. (2016) suggested that fast mesoscale processes can generate long-vertical wavelength waves. Spiga et al. (2012) also suggested that mesoscale processes are of topographic origin.

MAVEN observations provide further evidence that wave-induced variability is a ubiquitous feature of the planetary middle-to-upper atmospheres, as was predicted by GCM modeling (Miyoshi et al., 2014; Yiğit et al., 2009, 2012) and recently supported by observations in the terrestrial thermosphere (Forbes et al., 2016).

\section{Conclusions}

We have investigated global characteristics of wave perturbations in the Martian middle atmosphere at altitudes 20-140 km using MAVEN/IUVS stellar occultation measurements. The main results of this study are summarized as follows.

1. The observed temperature profiles demonstrate wave perturbations with peak amplitudes exceeding $20 \%$ of the mean background values for altitudes above $80 \mathrm{~km}$ on the nightside. This is larger than those in Earth's mesosphere and thermosphere $(\sim 5-13 \%)$.

2. Large wave activity has been observed in the northern low-latitude region and southern polar region at $L_{s}=0-180^{\circ}$. We found that the enhancement in northern hemisphere disappears at $L_{s}=180-360^{\circ}$. In contrast, the wave perturbations are significant in southern low-latitudes. These wave perturbations generate an instability layer around $70-100 \mathrm{~km}$.

3. Vertical wavenumber spectral power density in the Martian middle atmosphere shows a power-law dependence with a logarithmic spectral slope of -3 . This is similar to the Earth's atmosphere.

4. Our work shows differences in the spectral power density between altitudes $20-90$ and $70-140 \mathrm{~km}$. This result suggests that the strong $\mathrm{CO}_{2}$ 15-micron band cooling dissipates shorter waves, whereas the spectral power density of longer waves suggests that the amplitudes of unsaturated waves grow with height as they move toward the lower thermosphere. Our estimates basically support previous model-based findings (Eckermann et al., 2011).

Our result highlighted the distinctive behavior of Martian atmosphere. The strong solar heating in the tenuous atmosphere of Mars, in particular at perihelion in southern hemisphere $\left(L_{s}=180-360^{\circ}\right)$, can induce notable tidal waves and convective-induced gravity waves in the troposphere. The strong convection flow in the boundary layer may drive fast-propagating waves which propagate upward into the mesosphere and thermosphere. In the upper atmosphere, these waves become large enough to distort the background wind velocity and thermal structure significantly.

\section{Data Availability Statement}

All temperature profiles used in this study correspond to Level 2, version 13, revision 1 data provided by the Planetary Data System (PDS) (https://atmos.nmsu.edu/data_and_services/atmospheres_data/MAVEN/ stellar.html) (Schneider, N. et al., MAVEN IUVS Derived-level Data Product Bundle, urn:nasa:pds:maven. iuvs.processed 2015). Temperature disturbance stellar occultation data are available (https://doi.org/ 10.25810/cjvy-vv76), which are custom products which are primarily level 2 data, but the primary extension has been replaced with derived mean component and disturbance component of temperature profiles. 


\section{Acknowledgments}

This work was supported by Grant-inAid for Scientific Research (B) 15H03731, Scientific Research (A) 16H0229, Scientific Research (C) for Nos. 16K05566 and 19K03934 from JSPS, and Grant-in-Aid for Scientific Research on Innovative Areas for Nos. $18 \mathrm{H} 04453$ and $20 \mathrm{H} 04605$ from JSPS. The MAVEN project is supported by NASA through the Mars Exploration Program. This work was conducted under NASA's MAVEN Participating Scientist Program (proposal \#12MAVENPS12-0017, PI: K. Seki). HN is supported by the Astrobiology Center Program of National Institutes of Natural Science (NINS) (grant AB291015). HN would like to acknowledge Alexander S. Medvedev, Erdal Yiğit, Ben Johnston, and Zachariah Milby for their assistance in evaluating this paper.

\section{References}

Altieri, F., Spiga, A., Zasova, L., Bellucci, G., \& Bibring, J. P. (2012). Gravity waves mapped by the OMEGA/MEX instrument through $\mathrm{O}_{2}$ dayglow at 1.27 micron: Data analysis and atmospheric modeling. Journal of Geophysical Research, 117, E00J08. https://doi.org/10.1029/ 2012JE004065

Ando, H., Imamura, T., \& Tsuda, T. (2012). Vertical wavenumber spectra of gravity waves in the Martian atmosphere obtained from Mars Global Surveyor radio occultation data. Journal of the Atmospheric Sciences, 69(9), 2906-2912. https://doi.org/10.1175/JAS-D-11-0339.1

Ando, H., Imamura, T., Tsuda, T., Tellmann, S., Pätzold, M., \& Häusler, B. (2015). Vertical wavenumber spectra of gravity waves in the Venus atmosphere obtained from Venus Express radio occultation data: Evidence for saturation. Journal of the Atmospheric Sciences, 72(6), 2318-2329. https://doi.org/10.1175/JAS-D-14-0315.1

Barnes, J. R. (1900). Possible effects of breaking gravity waves on the circulation of the middle atmosphere of Mars. Journal of Geophysical Research, 95(B2), 1401-1421. https://doi.org/10.1029/jb095ib02p01401

Bougher, S. W., Jakosky, B., Halekas, J., Grebowsky, J., Luhmann, J., Mahaffy, P., et al. (2015). Early MAVEN Deep Dip campaign reveals thermosphere and ionosphere variability. Science, 350(6261), aad0459. https://doi.org/10.1126/science.aad0459

Bruinsma, S. L., \& Forbes, J. M. (2008). Medium- to large-scale density variability as observed by CHAMP. Space Weather, 6, S08002. https://doi.org/10.1029/2008SW000411

Chamberlain, J. W. (1963). Planetary coronae and atmospheric evaporation. Planetary and Space Science, 11(8), 901-960. https://doi.org/ 10.1016/0032-0633(63)90122-3

Collins, M., \& Smith, R. W. (2004). Evidence of damping and overturning of gravity waves in the arctic mesosphere: Na lidar and OH temperature observations. Journal of Atmospheric and Solar - Terrestrial Physics, 66(10), 867-879. https://doi.org/10.1016/j. jastp.2004.01.038

Creasey, J. E., Forbes, J. M., \& Hinson, D. P. (2006). Global and seasonal distribution of gravity wave activity in Mars' lower atmosphere derived from MGS radio occultation data. Geophysical Research Letters, 33, L01803. https://doi.org/10.1029/2005GL024037

Creasey, J. E., Forbes, J. M., \& Keating, G. M. (2006). Density variability at scales typical of gravity waves observed in Mars' thermosphere by the MGS accelerometer. Geophysical Research Letters, 33, L22814. https://doi.org/10.1029/GL027583

Eckermann, S. D., Ma, J., \& Zhu, X. (2011). Scale-dependent infrared radiative damping rates on Mars and their role in the deposition of gravity-wave momentum flux. Icarus, 211(1), 429-442. https://doi.org/10.1016/j.icarus.2010.10.029

England, S. L., Liu, G., Kumar, A., Mahaffy, P. R., Elrod, M., Benna, M., et al. (2019). Atmospheric tides at high latitudes in the Martian upper atmosphere observed by MAVEN and MRO. Journal of Geophysical Research: Space Physics, 124, 2943-2953. https://doi.org/ 10.1029/2019JA026601

England, S. L., Liu, G., Withers, P., Yiğit, E., Lo, D., Jain, S., et al. (2016). Simultaneous observations of atmospheric tides from combined in situ and remote observations at Mars from the MAVEN spacecraft. Journal of Geophysical Research, 121, 594-607. https://doi.org/ 10.1002/2016JE004997

England, S. L., Liu, G., Yiğit, E., Mahaffy, P. R., Elrod, M., Benna, M., et al. (2017). MAVEN NGIMS observations of atmospheric gravity waves in the Martian thermosphere. Journal of Geophysical Research, 122, 2310-2335. https://doi.org/10.1002/2016JA023475

Forbes (2002). Wave coupling in terrestrial atmospheres. In Atmospheres in the solar system: Comparative aeronomy (Vol. 130, pp. 171-190). American Geophysical Union. https:/www.wiley.com/en-us/Atmospheres\%in\%the\%Solar\%System\%3A\%Comparative\%Aeronomy-p9780875909899

Forbes, M. F., Bruinsma, S., \& Lemoine, F. G. (2006). Solar rotation effects on the thermospheres of Mars and Earth. Science, 312(5778), 1366-1368. https://doi.org/10.1126/science.1126389

Forbes, M. F., Bruinsma, S. L., Doornbas, E., \& Zhang, X. (2016). Gravity wave-induced variability of the middle thermosphere. Journal of Geophysical Research: Space Physics, 121, 6914-6923. https://doi.org/10.1002/2016JA022923

Forget, F., Montmessin, F., Bertaux, J. L., González-Galindo, F., Lebonnois, S., Quémerais, E., et al. (2009). Density and temperatures of the upper Martian atmosphere measured by stellar occultations with Mars Express SPICAM. Journal of Geophysical Research, 114 , E01004. https://doi.org/10.1029/2008JE003086

Fritts, D. C. (2011). Gravity wave influences in the thermosphere and ionosphere: Observations and recent modeling. Aeronomy of the Earth Atmosphere and Ionosphere, 109-130. https://doi.org/10.1007/978-94-007-0326-1_8

Fritts, D. C., \& Alexander, M. J. (2003). Gravity wave dynamics and effects in the middle atmosphere. Reviews of Geophysics, $41(1), 1003$. https://doi.org/10.1029/2001RG000106

Fritts, D. C., Wang, L., \& Tolson, R. H. (2006). Mean and gravity wave structures and variability in the Mars upper atmosphere inferred from Mars Global Surveyor and Mars Odyssey aerobraking densities. Journal of Geophysical Research, 111, A12304. https://doi.org/ 10.1029/2006JA011897

González-Galindo, F., Määttänen, A., Forget, F., \& Spiga, A. (2011). The Martian mesosphere as revealed by $\mathrm{CO}_{2}$ cloud observations and General Circulation Modeling. Icarus, 216(1), 10-22. https://doi.org/10.1016/j.icarus.2011.08.006

Gröller, H., Montmessin, F., Yelle, R. V., Lefèvre, F., Forget, F., Schneider, N. M., et al. (2018). MAVEN/IUVS stellar occultation measurements of Mars atmospheric structure and composition. Journal of Geophysical Research, 123, 1449-1483. https://doi.org/10.1029/ 2017JE005466

Gröller, H., Yelle, R. V., Koskinen, T. T., Montmessin, F., Lacombe, G., Schneider, N. M., et al. (2015). Probing the Martian atmosphere with MAVEN/IUVS stellar occultations. Geophysical Research Letters, 42, 9064-9070. https://doi.org/10.1002/2015GL065294

Heavens, N. G., Kass, D. M., Kleinböhl, A., \& Schofield, J. T. (2020). A multiannual record of gravity wave activity in Mars's lower atmosphere from on-planet observations by the Mars Climate Sounder. Icarus, 341, 113630. https://doi.org/10.1016/j.icarus.2020.113630

Heavens, N. G., Richardson, M. I., Lawson, W. G., Lee, C., McCleese, D. J., Kass, D. M., et al. (2010). Convective instability in the Martian middle atmosphere. Icarus, 208(2), 574-589. https://doi.org/10.1016/j.icarus.2010.03.023

Hocke, H., \& Schlegel, K. (1996). A review of atmospheric gravity waves and travelling ionospheric disturbances: 1982-1995. Annales Geophysicae, 14, 917-940. https://doi.org/10.1007/s00585-996-0917-6

Imamura, T., \& Ogawa, T. (1995). Radiative damping of gravity waves in the terrestrial planetary atmospheres. Geophysical Research Letters, 22(3), 267-270. https://doi.org/10.1029/94GL02998

Imamura, T., Watanabe, A., \& Maejima, Y. (2016). Convective generation and vertical propagation of fast gravity waves on Mars: One- and two-dimensional modeling. Icarus, 267, 51-63. https://doi.org/10.1016/j.icarus.2015.12.005

Jakosky, B. M., Brain, D., Chaffin, M., Curry, S., Deighan, J., Grebowsky, J., et al. (2018). Loss of the Martian atmosphere to space: Present-day loss rates determined from MAVEN observations and integrated loss through time. Icarus, 315, 146-157. https://doi.org/ 10.1016/j.icarus.2018.05.030 
Jakosky, B. M., Grebowsky, J. M., Luhmann, J. G., Connerney, J., Eparvier, F., Ergun, R., et al. (2015). MAVEN observations of the response of Mars to an interplanetary coronal mass ejection. Science, 350(6261), aad0210. https://doi.org/10.1126/science.aad0210

John, S. R., \& Kumar, K. K. (2012). TIMED/SABER observations of global gravity wave climatology and their interannual variability from stratosphere to mesosphere lower thermosphere. Climate Dynamics, 39(6), 1489-1505. https://doi.org/10.1007/s00382-012-1329-9

Joshi, M. M., Lawrence, B. N., \& Lewis, S. R. (1995). Gravity wave drag in three-dimensional atmospheric models of Mars. Journal of Geophysical Research, 100(E10), 21,235-21,245. https://doi.org/10.1029/95JE02486

Kuroda, T., Medvedev, A. S., Yiğit, E., \& Hartogh, P. (2015). A global view of gravity waves in the Martian atmosphere inferred from a high-resolution general circulation model. Geophysical Research Letters, 42, 9213-9222. https://doi.org/10.1002/2015GL066332

Kuroda, T., Medvedev, A. S., Yiğit, E., \& Hartogh, P. (2016). Global distribution of gravity wave sources and fields in the Martian atmosphere during equinox and solstice inferred from a high-resolution general circulation model. Journal of the Atmospheric Sciences, 73(12), 4895-4909. https://doi.org/10.1175/JAS-D-16-0142.1

Kuroda, T., Yiğit, E., \& Medvedev, A. S. (2019). Annual cycle of gravity waves activity derived from a high-resolution Martian general circulation model. Journal of Geophysical Research, 124, 1618-1632. https://doi.org/10.1029/2018JE005847

Kursinski, E. R., Haji, G. A., Schofiled, J. T., Linfield, R. P., \& Hardy, K. R. (1997). Observing Earth's atmosphere with radio occultation measurements using the Global Positioning System. Journal of Geophysical Research, 102(D19), 23429-23465. https://doi.org/10.1029/ 97JD01569

Liu, A. Z., Roble, R. G., Hecht, J. H., Larsen, M. F., \& Gardner, C. S. (2004). Unstable layers in the mesopause region observed with Na lidar during the Turbulent Oxygen Mixing Experiment (TOMEX) campaign. Journal of Geophysical Research, 109, D02S02. https://doi.org/ $10.1029 / 2002 J D 003056$

Liu, X., Yue, J., Xu, J., Garcia, R. R., Russell, J. M. III, Mlynczak, M., et al. (2017). Variations of global gravity waves derived from 14 years of SABER temperature observations. Journal of Geophysical Research, 122, 6231-6249. https://doi.org/10.1002/2017/JD026604

Magalhaes, J. A., Schofield, J. T., \& Seiff, A. (1999). Results of the Mars Pathfinder atmospheric structure investigation. Journal of Geophysical Research, 104(E4), 8943-8955. https://doi.org/10.1029/1998JE900041

McClees, D. J., Schofield, J. T., Taylor, F. W., Abdou, W. A., Aharonson, O., Bandfield, D., et al. (2008). Intense polar temperature inversion in the middle atmosphere on Mars. Nature Geoscience, 1(11), 745-749. https://doi.org/10.1038/ngeo332

McClintock, W. E., Schneider, N. M., Holsclaw, G. M., Clarke, J. T., Hoskins, A. C., Stewart, I., et al. (2014). The Imaging Ultraviolet Spectrograph (IUVS) for the MAVEN mission. Space Science Reviews, 195(1-4), 75-124. https://doi.org/10.1007/s11214-014-0098-7

McDunn, T. L., Bougher, S. W., Murphy, J., Smith, M. D., Forget, F., Bertaux, J.-L., \& Montmessin, F. (2006). Simulating the density and thermal structure of the middle atmosphere $(\sim 80-130 \mathrm{~km})$ of Mars using the MGCM-MTGCM: A comparison with MEX/SPICAM observations. Icarus, 206(1), 5-17. https://doi.org/10.1016/j.icarus.2009.06.034

Medvedev, A. S., González-Galindo, F., Yiğit, E., Feofilov, A. G., Forget, F., \& Hartogh, P. (2015). Cooling of the Martian thermosphere by $\mathrm{CO}_{2}$ radiation and gravity waves: An intercomparison study with two general circulation models. Journal of Geophysical Research: Planets, 120, 913-927. https://doi.org/10.1002/2015JE004802

Medvedev, A. S., Nakagawa, H., Mockel, C., Yiğit, E., Kuroda, T., Hartogh, P., et al. (2016). Comparison of the Martian thermospheric density and temperature from IUVS/MAVEN data and general circulation modeling. Geophysical Research Letters, 43, 3095-3104. https://doi.org/10.1002/2016GL068388

Medvedev, A. S., Yiğit, E., \& Hartogh, P. (2011). Estimates of gravity wave drag on Mars: Indication of a possible lower thermospheric wind reversal. Icarus, 211, 909-912. https://doi.org/10.1016/j.icarus2010.10.013

Medvedev, A. S., Yiğit, E., Hartogh, P., \& Becker, E. (2011). Influence of gravity waves on the Martian atmosphere: General circulation modeling. Journal of Geophysical Research, 116, E10004. https://doi.org/10.1029/2011JE003848

Michaels, T., \& Rafkin, S. C. (2004). Large-eddy simulation of atmospheric convection on Mars. Quarterly Journal of the Royal Meteorological Society, 130(599), 1251-1274. https://doi.org/10.1256/qj.02.169

Miyoshi, Y., \& Fujiwara, H. (2008). Gravity waves in the thermosphere simulated by a general circulation model. Journal of Geophysical Research, 113, D01101. https://doi.org/10.1029/2007JD008874

Miyoshi, Y., \& Fujiwara, H. (2009). Gravity waves in the equatorial thermosphere and their relation to lower atmospheric variability. Earth, Planets and Space, 61(4), 471-478. https://doi.org/10.1186/BF03353164

Miyoshi, Y., Fujiwara, H., Jin, H., \& Shinagawa, H. (2014). A global view of gravity waves in the thermosphere simulated by a general circulation model. Journal of Geophysical Research, 119, 5807-5820. https://doi.org/10.1002/2014JA019848

Montmessin, F., Korablev, O., Lefèvre, F., Bertaux, J. L., Fedorova, A., Trokhimovskiy, A., et al. (2017). SPICAM on Mars Express: A 10 year in-depth survey of the Martian atmosphere. Icarus, 297, 195-216. https://doi.org/10.1016/j.icarus.2017.06.022

Montmessin, F., Quémerais, E., Bertaux, J. L., Korablev, O., Rannou, P., \& Lebonnois, S. (2006). Stellar occultations at UV wavelengths by the SPICAM instrument: Retrieval and analysis of Martian haze profiles. Journal of Geophysical Research, 111, E09S09. https://doi.org/ 10.1029/2005JE002662

Nakagawa, H., Jain, S. K., Schneider, N. M., Montmessin, F., Yelle, R. V., Jiang, F., et al. (2020). A warm layer in the nightside mesosphere of Mars. Geophysical Research Letters, 47, e2019GL085646. https://doi.org/10.1029/2019GL085646

Odaka, M., Nakajima, M., Takehiro, S., Ishiwatari, M., \& Hayashi, Y. (1998). A numerical study of the Martian atmospheric convection with a two-dimensional anelastic model, Earth. Planets and Space, 50(5), 431-437. https://doi.org/10.1186/BF03352130

Quémerais, E., Bertaux, J. L., Korablev, O., Dimarellis, E., Cot, C., Sandel, B. R., \& Fussen, D. (2006). Stellar occultations observed by SPICAM on Mars Express. Journal of Geophysical Research, 111, E09S04. https://doi.org/10.1029/2005je002604

Sato, K., Watanabe, S., Kawatani, Y., Tomikawa, Y., Miyazaki, K., \& Takahashi, M. (2009). On the origins of mesospheric gravity waves. Geophysical Research Letters, 36, L19801. https://doi.org/10.1029/2009GL039908

Seiff, A., \& Kirk, D. B. (1976). Structure of Mars' atmosphere up to 100 kilometers from the entry measurements of Viking 2. Science, 194(4271), 1300-1303. https://doi.org/10.1126/science.194.4271.1300

Siddle, A. G., Mueller-Wodarg, I. C. F., Stone, S. W., \& Yelle, R. V. (2019). Global characteristics of gravity waves in the upper atmosphere of Mars as measured by MAVEN/NGIMS. Icarus, 333, 12-21. https://doi.org/10.1016/j.icarus.2019.05.021

Smith, S. A., Fritts, D. C., \& Vanzandt, T. E. (1987). Evidence for a saturated spectrum of atmospheric gravity waves. Journal of the Atmospheric Sciences, 44(10), 1404-1410. https://doi.org/10.1175/1520-0469(1987)044<1404:EFASSO>2.0.CO;2

Spiga, A., González-Galindo, F., López-Valverde, M. A., \& Forget, F. (2012). Gravity waves, cold pockets and $\mathrm{CO}_{2}$ clouds in the Martian mesosphere. Geophysical Research Letters, 39, L02201. https://doi.org/10.1029/2011GL050343

Suzuki, S., Shiokawa, K., Otsuka, Y., Ogawa, T., Kubota, M., Tsutsumi, M., et al. (2007). Gravity wave momentum flux in the upper mesosphere derived from $\mathrm{OH}$ airglow imaging measurements. Earth, Planets and Space, 59(5), 421-428. https://doi.org/10.1186/ BF03352703 
Tellmann, S., Pätzold, M., Häusler, B., Hinson, D. P., \& Tyler, G. L. (2013). The structure of Mars lower atmosphere from Mars Express Radio Science (MARS) occultation measurements. Journal of Geophysical Research, 118, 306-320. https://doi.org/10.1002/jgre.20058

Terada, N., Leblanc, F., Nakagawa, H., Medvedev, A. S., Yiğit, E., Kuroda, T., et al. (2017). Global distribution and parameter dependences of gravity wave activity in the Martian upper thermosphere derived from MAVEN/NGIMS observations. Journal of Geophysical Research: Space Physics, 122, 2374-2397. https://doi.org/10.1002/2016JA023476

Tsuda, T., \& Nishida, M. (2000). A global morphology of gravity wave activity in the stratosphere revealed by the GPS occultation data (GPS/MET). Journal of Geophysical Research, 105(D6), 7257-7273. https://doi.org/10.1029/1999JD901005

Tsuda, T., Vanzandt, T. E., Mizumoto, M., Kato, S., \& Fukao, S. (1991). Spectral analysis of temperature and Brunt-Väisälä frequency fluctuations observed by radiosondes. Journal of Geophysical Research, 96(D9), 17265-17278. https://doi.org/10.1029/91JD01944

Vals, M., Spiga, A., Forget, F., Millour, E., Montabone, L., \& Lott, F. (2019). Study of gravity waves distribution and propagation in the thermosphere of Mars based on MGS, MRO and MAVEN density measurements. Planetary and Space Science, 178, 104708. https://doi. org/10.1016/j.pss.2019.104708

Williams, B. P., Fritts, D. C., She, C. Y., \& Goldberg, R. A. (2006). Gravity wave propagation through a large semidiurnal tide and instabilities in the mesosphere and lower thermosphere during the winter 2003 MaCWAVE rocket campaign. Annales de Geophysique, 24(4), 1199-1208. https://doi.org/10.5194/angeo-24-1199-2006

Wilson, R. J. (1997). A general circulation model simulation of the Martian polar warming. Geophysical Research Letters, 24(2), 123-126. https://doi.org/10.1029/96GL03814

Withers, P., Pratt, R., Bertaux, J.-L., \& Montmessin, F. (2011). Observations of thermal tides in the middle atmosphere of Mars by the SPICAM instrument. Journal of Geophysical Research, 116, E1105. https://doi.org/10.1029/2011JE003847

Yamashita, C., England, S. L., Immel, T. J., \& Chang, L. C. (2013). Gravity wave variations during elevated stratopause events using SABER observations. Journal of Geophysical Research, 118, 5287-5303. https://doi.org/10.1002/jgrd.50474

Yiğit, E., England, S. L., Liu, G., Medvedev, A. S., Mahaffy, P. R., Kuroda, T., \& Jakosky, B. M. (2015). High-altitude gravity waves in the Martian thermosphere observed by MAVEN/NGIMS and modeled by a gravity wave scheme. Geophysical Research Letters, 42 , 8993-9000. https://doi.org/10.1002/2015GL065307

Yiğit, E., Knízôvá, P. K., Georgieva, K., \& Ward, W. (2016). A review of vertical coupling in the Atmosphere-Ionosphere system: Effects of waves, sudden stratospheric warmings, space weather, and of solar activity. Journal of Atmospheric and Solar - Terrestrial Physics, 141, 1-12. https://doi.org/10.1016/j.jastp.2016.02.011

Yiğit, E., Medvedev, A. S., Aylward, A. D., Hartogh, P., \& Harris, M. J. (2009). Modeling the effects of gravity wave momentum deposition on the general circulation above the turbopause. Journal of Geophysical Research, 114, D07101. https://doi.org/10.1029/2008JD011132

Yiğit, E., Medvedev, A. S., Aylward, A. D., Ridley, A. J., Harris, M. J., Moldwin, M. B., \& Hartogh, P. (2012). Dynamical effects of interna gravity waves in the equinoctial thermosphere. Journal of Atmospheric and Solar - Terrestrial Physics, 90-91, 104-116. https://doi.org/ 10.1016/j.jastp.2011.11.014

Yiğit, E., Medvedev, A. S., \& Hartogh, P. (2015). Gravity waves and high-altitude CO2 ice cloud formation in the Martian atmosphere. Geophysical Research Letters, 42, 4294-4300. https://doi.org/10.1002/2015GL064275 